\section{Dimensão formativa da escrita de si: vivências e necessidades de professores em formação inicial}

Formative dimension of self-writing: livingness and teachers' necessities in initial formation

Bruna Viedo KICH (UFSM) brunavkich@gmail.com

Adriana Claudia MARTINS (UFSM) teacheradrianacm@hotmail.com

Recebido em: 30 de maio de 2018. Aceito em: 17 de set. de 2018.
KICH, Bruna Viedo; MARTINS, Adriana Claudia. Dimensão formativa da escrita de si: vivências e necessidades de professores em formação inicial. Entrepalavras, Fortaleza, v. 8, n. 3, p. 161-180, out-dez/2018.

Resumo: Este estudo tem como objetivo avaliar alguns aspectos relevantes das narrativas de professores em formação inicial, os quais envolvem não somente o movimento de escritura de diários de classe e a resistência à escrita, mas também a atividade de leitura desses diários e a tomada de consciência em relação aos acontecimentos da aprendizagem da docência. O contexto da realização da pesquisa deu-se durante o processo formativo de professores nas atividades realizadas no Estágio Supervisionado em Letras, em uma universidade pública do Rio Grande do Sul. Zabalza (2004), Telles (2002), Freire (1995, 1996) e Bakhtin (1992, 2010) são alguns dos teóricos que sustentam esta discussão. Com uma abordagem metodológica qualitativa, de cunho sociocultural (BAKHTIN, 2010, BOLZAN, 2006), elaboramos três categorias de análise: os enfrentamentos da vivência em sala de aula; as frustrações que tangenciaram a formação docente e a necessidade de readaptarse e emergir. O estudo revela que a formação inicial deprofessores desenha-sena relação entre os percursos de formação e de autoformação, e nas experiências pessoais, que envolvem tanto os conhecimentos adquiridos quanto estudantes da Educação Básica como a trajetória profissional. Constatamos que o estudante de Letras, ao escrever seus diários e refletir sobre a própria escrita, foi-se constituindo como um profissional autocrítico.

Palavras-chave: Processo formativo docente. Diário de classe. Aprendizagem da docência. 
v. 8 (3)

161-180

out-dez

2018

Abstract: This study aims to show the relevant aspects highlighted in teachers' narratives in initial formation, which does not involve only the writing of these class diaries and the resistance to them, but also the activity of reading them and the awareness in relation to the teaching-learning events. The research context was situated during the teachers' formative process, therefore, in activities performed in the Supervised Teaching Practice during the Language Course, in a public university, in Rio Grande do Sul state, Brazil. Zabalza (2004), Telles (2002), Freire (1995, 1996) and Bakhtin $(1992,2010)$ are some of the theorists who brace this discussion. We elaborated three categories of analysis considering a social-cultural qualitative methodological approach (BAKHTIN, 2010, BOLZAN, 2006), the confrontations in the classroom livingness, the frustrations that vectored the teaching formation, and the necessity of readapting and emerging. The study reveals that the initial teachers' formation designs itself on the relation among the paths of formation and selfformation, in personal experiences, involving the knowledge as students that were in Primary Education and the professional history. It was determined that the Language Course undergraduate student was constituting him/herself and dialoguing by writing their diaries, putting him/herself as a self-critic professional.

Keywords: Teaching the formative process. Class diary. Teaching-learning.

\section{Introdução}

Com o objetivo de explicitar alguns aspectos relevantes presentes nas narrativas de professores em formação inicial, os quais envolvem não somente o movimento de escritura e a resistência à atividade de escrita, mas também a atividade de leitura dos diários de classe e a tomada de consciência em relação aos acontecimentos da aprendizagem da docência, consideramos o processo formativo de professores durante o Estágio Supervisionado em Letras, em que a aprendizagem da docência passa por um processo que exige tomar consciência da realidade escolar e da conjuntura política da educação.

A atividade formativa de professores, de acordo com Leffa (2008) distingue-se de um mero processo formativo, pois é preciso refletir e compreender as razões pelas quais as ações são feitas de determinados modos e não de outros. Assim, ao estar imerso no processo formativo docente e ser, além de professor na sala de aula da escola pública, também um acadêmico na graduação, a formação é revisitada a todo o momento e refletida em si e no outro.

As narrativas de profissionais em formação inicial são apresentadas neste estudo a fim de que possamos refletir e compreender o contexto de cada situação, de cada fala e da posição axiológica, portanto do lugar em que cada autor da narrativa se coloca. A escritura docente proporciona ao professor "revisar elementos do seu mundo pessoal que frequentemente permanecem ocultos à sua própria percepção enquanto está envolvido nas ações cotidianas de trabalho" (ZABALZA, 2004, p.17). 
A narrativa docente é, portanto, um instrumento de viabilização do movimento reflexivo do professor sobre o próprio processo formativo, o qual está relacionado à tomada de consciência de um contexto e ato profissional (PORLÁN; MARTÍN, 1997, p.23) ${ }^{1}$.

Nesse sentido, esse estudo considera as narrativas docentes de seis estudantes de uma universidade do interior do Rio Grande do Sul e pondera a pertinência dessa ferramenta no processo formativo. Tanto a escritura de diários de classe, quanto a leitura destes compunham uma atividade de reflexão apresentada semanalmente nas aulas de Estágio Supervisionado, para que professores em formação inicial compartilhassem com os colegas as experiências vivenciadas na docência na escola e para que refletissem sobre a própria prática pedagógica em sala de aula. A tessitura dos diários tem como proposta o narrador crítico, que, ao distanciar-se de cada situação, pode refletir mais imerso em suas próprias ações, questionando-se para, então, emergir transformando seu fazer docente e se colocando autocrítico no próprio processo formativo.

Quanto à sua organização, este texto apresenta, além dessas palavras iniciais, o caminho metodológico, o qual explicita como a análise foi organizada e como as narrativas docentes foram consideradas para que a pesquisa se concretizasse. Desse modo, categorias emergiram no desenho da pesquisa, as quais são explicadas à luz de teorias que consideram o uso da escrita reflexiva no processo formativo docente. A escrita deste artigo se fecha ao enunciar que a atividade narrativa no diário de classe permite uma aprendizagem crítico-reflexiva da docência e ao sublinhar que este instrumento é pertinente na formação de professores.

\section{As escrituras de si: a abordagem metodológica}

A prática metodológica com narrativas tem-se difundido nas temáticas de educação inicial ou continuada, visto que textos de caráter (auto) biográfico consideram o contexto histórico social dos professores e também as relações que os circundam (SOUZA, 2014). No decorrer desse estudo, por exemplo, as recorrências nas narrativas revelam como os professores em formação inicial passam por um processo reflexivo que pode ser compartilhado. Este movimento está relacionado com a

\footnotetext{
1 "És un guía para la reflexión sobre la práctica, favoreciendo la toma del conciencia del profesor sobre su proceso de evolución y sobre sus modelos de referencia" (PORLÁN; MARTÍN, 1997, p.23). (tradução das autoras deste artigo).
} 
v. 8 (3)

161-180 out-dez 2018

escrita de diários ${ }^{2}$, bem como com o papel que esses docentes atribuem à escrita reflexiva durante o processo formativo.

Tomamos emprestadas as palavras de Chené (2014, p.128) que elucidam esse discurso, ao afirmar que o "percurso que o narrador realiza é de si para consigo". Ainda assim, é possível que a escritura, quando compartilhada, traga o dito do autor/criador de uma maneira que faça sentido àquelas outras pessoas que ouvem a narrativa. Portanto, a partir da escuta reflexiva de si e da leitura, também aqueles Outros que ouvem seu colega olham para si, pois a trajetória daquele que lê compreende um sentido de caráter pessoal para o ouvinte. Compreendemos, assim, que há um movimento heterobiográfico, no qual a narrativa de si é praticada através do conflito com a narrativa do Outro (DELORYMOMBERGER, 2008).

Consideramos os estudos de Bakhtin (1992, p.43), ao afirmar que "o sujeito como tal não pode ser percebido e estudado a título de coisa porque, como sujeito, não pode, permanecendo sujeito, ficar mudo; consequentemente, o conhecimento que se tem dele só pode ser dialógico".

Logo, esse estudo está fundamentado em uma pesquisa qualitativa de cunho sociocultural (BAKHTIN, 2010, BOLZAN, 2006) que visa considerar as narrativas a partir das recorrências reflexivas nos diários de classe.

As narrativas têm significado peculiar, pois trazem ecos da interação e das vivências que se colocam em diálogo, e são, de acordo com Telles (2002, p.16), "espaços para a criação de oportunidades para professores e professores recuperarem, reconstruírem e representarem os significados de suas experiências pessoais, pedagógicas e linguísticas". O estudo que contempla narrativas e que traz o momento de negociação entre os sujeitos que compartilham de suas vivências, pessoais e profissionais é explicado por Connelly e Clandinin (1995, p. 12) como "uma forma de caracterizar os fenômenos da experiência humana e, portanto, seu estudo é apropriado em muitos campos das ciências sociais". ${ }^{3}$ Rodrigues e Prado (2015) apontam que o método narrativo é uma ferramenta valiosa de análise discursiva, pois, além de apontar sentido às experiências vividas, apresenta uma tautocronia ao ser método investigativo, objeto de estudo e maneira de realizar um relatório investigativo.

\footnotetext{
${ }^{2} \mathrm{O}$ uso da expressão diário reflexivo de classe, ou apenas diário de classe, refere-se a narrativas de caráter escrito, utilizadas por professores como forma de registro de seu cotidiano escolar, suas práticas pedagógicas e sua elaboração e planejamento de aula.

3 "[...] es una forma de caracterizar los fenómenos de la experiencia humana y, por tanto, su estudio es apropiado en muchos campos da las ciencias sociales" (CONNELLY; CLANDININ, 1995, p.12) (tradução das autoras deste artigo).
} 
Ao entrelaçar a escuta atenciosa de quem compartilha da experiência do Outro4 , daquele que lê seu diário, os colegas vão-se colocando nos lugares dos colaboradores, narrando justificativas no silêncio compreensivo e reflexivo. Assim, há elementos importantes a serem considerados nesta troca significativa e nesse caminho metodológico, como a igualdade "entre os participantes, a situação de atenção mútua, e os sentimentos de conexão" (CONNELLY; CLANDININ, 1995, p. 19) $)^{5}$.

Dessa forma, das escritas e leituras, nosso estudo considerou as recorrências nos discursos dos anunciadores, para, assim, organizar a categorização com base na apreciação semântica dos ditos. Conforme a amplitude dos diários reflexivos, visto que o tema não era préestruturado, uma leitura inicial agrupou temas recorrentes ao longo das narrativas. Levamos em consideração as afinidades de discurso e de sentido maiores para definição das categorias de análise. As leituras foram retomadas levando em conta as situações explícitas e nelas foi possível reconhecer os chamados eixos articuladores, que são as recorrências de sentido e de significado que ligavam as categorias de análise a unidades menores de sentido ou elementos categoriais (conforme mostra o Quadro 1). Nesse estudo, utilizamo-nos de três categorias de análise explicitadas no Quadro 1. O arranjo exposto explicita o estudo conforme as categorias, os eixos articuladores e os elementos categoriais, os quais foram organizados, a fim de realizarmos a análise e discussão.

\footnotetext{
${ }_{4}^{4}$ Ao longo do texto, a escrita da palavra Outro com letra maiúscula tem uma razão valorativa, pois apreendemos que a relação deve se dar de modo a considerar este Outro como aquele que permite a tomada de consciência do sujeito que fala.

5 "[...] entre los participantes, la situación de atención mutua, y los sentimientos de conexión" (CONNELLY; CLANDININ, 1995, p. 19) (tradução das autoras deste artigo).
} 
v. 8 (3)

$161-180$

out-dez

2018

Quadro 1 - Categorias de análise e eixos articuladores

\begin{tabular}{|c|c|c|}
\hline CATEGORIAS & $\begin{array}{c}\text { EIXOS } \\
\text { ARTICULADORES }\end{array}$ & ELEMENTOS CATEGORIAIS \\
\hline $\begin{array}{c}1^{\mathrm{a}} \text { categoria: } \\
\text { Os enfrentamentos da } \\
\text { vivência em sala de aula }\end{array}$ & $\begin{array}{l}\text { 1.Um vislumbre: os } \\
\text { primeiros momentos com } \\
\text { a turma e o sentimento de } \\
\text { insegurança; } \\
\text { 2. A (in)disciplina em sala } \\
\text { de aula. }\end{array}$ & $\begin{array}{l}\text { - experiências de } \\
\text { nervosismo e dúvidas } \\
\text { - questiona as práticas dos } \\
\text { alunos }\end{array}$ \\
\hline $\begin{array}{c}2^{\mathrm{a}} \text { categoria: } \\
\text { As frustrações que } \\
\text { tangenciaram a formação } \\
\text { docente }\end{array}$ & $\begin{array}{l}\text { 1. A elaboração e a } \\
\text { implementação do plano de } \\
\text { aula; } \\
\text { 2. O sentimento de } \\
\text { impotência. }\end{array}$ & $\begin{array}{l}\text { - o plano de aula como eixo } \\
\text { norteador } \\
\text { - atividades que não } \\
\text { correram como o planejado } \\
\text { - experiências de } \\
\text { improvisação e reelaboração } \\
\text { do plano de aula no } \\
\text { momento da aula; } \\
\text { - o sentimento de } \\
\text { frustração por atividades } \\
\text { que não correram como o } \\
\text { esperado }\end{array}$ \\
\hline $\begin{array}{c}3^{\mathrm{a}} \text { categoria: } \\
\text { A necessidade de } \\
\text { readaptar-se e emergir }\end{array}$ & $\begin{array}{l}\text { 1. O olhar para o Outro } \\
\text { 2. A tomada de consciência }\end{array}$ & $\begin{array}{l}\text { - O sentimento de empatia } \\
\text { - A compreensão acerca do } \\
\text { contexto social } \\
\text { - O entender o papel como } \\
\text { professor } \\
\text { - A compreensão do papel } \\
\text { da escola no âmbito social. }\end{array}$ \\
\hline
\end{tabular}

A discussão teórico-analítica que se segue considera as categorias de análise, os eixos e os elementos categoriais descritos e exemplifica as recorrências de sentido e significado a partir de fragmentos de narrativas dos professores em formação inicial.

\section{Os enfrentamentos da vivência em sala de aula}

Chamamos a primeira categoria de os enfrentamentos da vivência em sala de aula, mas também poderíamos chamar de os enfrentamentos do self em vivência em sala de aula, pois, quando falamos em educação, há um largo âmbito semântico e semiótico envolto nesse termo. Pensemos então: quais termos e/ou imagens estão atreladas nas nossas mentes quando dizemos sala de aula, estudante, professor, professora? Quando tratamos de atribuir sentido às coisas do mundo, atribuímos um universo de conceitos que nos compõem - crenças, ideologias, experiências. Dessa forma, o que nós acreditamos e a forma como nós olhamos o mundo não é ao acaso - afinal, "nenhuma 
linguagem está ausente de ideologia" (MOISÉS, 2013 p. 66-67). Somos, portanto, um misturado de coisas, um misturado de experiências. E mais: um misturado de pessoas.

Então, questionamos: como um universitário ou uma universitária, em seu processo de Estágio de docência, constitui-se educador, dado que ainda é um estudante? Como o próprio professor em formação inicial projeta, atua e reflete as suas ações? Arriscamos dizer neste eixo que é nele que se encontra o medo do desconhecido; a hierarquia escolar tão conhecida e, ao mesmo tempo, tão nova na assimetria de poder que o sujeito representa; o conceito de disciplina na escola e a necessidade de manter o controle ou restaurar a ordem. Dessa forma, quem se enfrenta na sala de aula é o ser professor, não enfrentamos a um Outro. Somos nós mesmos que nos enfrentamos todos os dias e nos constituímos desta necessidade de [des]construção. Confrontamos e nos deparamos com nossa própria identidade, crenças, limitações de entendimento do que pode ser certo ou errado.

Dado o conceito de Nóvoa (1995, p.16), compreendemos que "identidade não é um dado adquirido, não é uma propriedade, não é um produto [...] é um lugar de lutas e conflitos, é um espaço de construção de maneiras de ser e estar na profissão". Por isso, trazemos aqui presenças de sentido em recorrências sem buscar juízo de valor, porque entendemos cada sujeito como único e cada um desses seres no trilhar da composição de suas identidades, as quais apreendemos a partir dos estudos de Nóvoa (1995) e de Pollak (1992). Assim, consideramos as trajetórias pessoais e profissionais dos professores em formação inicial, seus saberes, valores, ideologias e muito mais.

No primeiro eixo desta categoria de análise, um vislumbre: os primeiros momentos com a turma e o sentimento de insegurança, experiências de nervosismo e dúvidas foram narradas: questionar a própria capacidade, a conduta ética e moral que cada instituição requer, entre outros fatos foram os sentimentos de estranhamento apontados. Neste viés reflexivo e no que concerne aos primeiros anos de docência, Garcia (1999, p.13) aponta que esse é "um período de tensões e aprendizagens intensivas em contextos geralmente desconhecidos, e durante o qual os professores principiantes devem adquirir conhecimento profissional além de manter um certo equilíbrio". É essa tentativa de adquirir o conhecimento e manter-se em equilíbrio nos primeiros contatos com a escola que podemos conferir nos excertos narrativos, de Helena e Simone, que seguem: 
V. 8 (3)

161-180 out-dez 2018

Me questionei ${ }^{6}$ também se eles faziam ideia de que eu estava nervosa, pois todos nós como humanos ficamos nervosos uma vez ou outra. Mas tentando manter a calma, entrei na escola.. [...]Entrei para a sala com o meu estômago rodando de novo - entendi que hoje a aula seria longa (Helena ${ }^{7}$ )

Fiquei com muitas dúvidas em como lidar com eles, e depois de minha primeira aula ministrada achei que não conseguiria dar a segunda (Simone)

A experiência dos primeiros momentos em uma sala de aula talvez não os primeiros momentos para quem já conhecia a docência de cursos de línguas, mas mediado pela diferença de contexto - caminha no terreno da insegurança; observação explicada pelo fato de que somos humanos. Estamos à mercê de diversos sentimentos e emoções. Quando estamos frente a um Outro, geralmente apontamos a velha posição hierárquica de estudante/professor, mas, como bem observado por Helena, somos apenas um ser humano - frente a outros seres humanos e, assim, vivenciamos as mais diversas sensações.

Para Simone, no entanto, o dilema é a constituição dessa hierarquia que a protege de alguma forma. A escolha lexical lidar, ao invés de conviver, ensinar, aprender, mostra-nos que, nesse momento, a necessidade dessa professora em formação é afirmarse como professora em uma posição de certezas com aqueles Outros seres humanos que estão vivenciando este processo de formação identitária com ela (NÓVOA, 1995). Uma construção "que se produz em referência aos outros, em referência aos critérios de aceitabilidade, de admissibilidade, de credibilidade, e que se faz por meio da negociação direta com outros" (POLLAK, 1992, p. 204). Em um outro momento, já não confrontada pela insegurança, a professora em formação inicial questiona as práticas não aceitas em sala de aula pela professora regente da turma e interroga sua própria maturidade, já que ela tem um hábito em comum com alguns dos estudantes do sexto ano escolar:

\footnotetext{
${ }^{6}$ Consideramos a enunciação conforme a escrita do diário na sua originalidade, portanto, não fizemos interferências ou correções gramaticais, considerando que este não seria nosso objeto de análise.
}

7 Os nomes dos professores e das professoras são meramente ilustrativos. 
Percebi que ela não deixa mascar chiclete em sala, e fiquei receosa. Estou ocupando o espaço do purgatório, lá sou professora, mas aqui também sou estudante. E me sinto hipócrita pedindo que alguém não masque chiclete. Eu gosto de chiclete! Acho que estou entrando em um conflito quanto a minha maturidade para assumir o posto (Helena)

Helena olha para si quando reconhece que as práticas em aula realizadas por seus alunos dizem respeito, de certo modo, ao comportamento que também ela tem em alguns momentos em sua rotina. Então, a professora em formação inicial olha para aquilo que a regente entende por (in)disciplina dos estudantes e, a partir de si, reflete e busca se questionar para compreender esta situação.

No segundo eixo desta primeira categoria de análise, a (in) disciplina em sala de aula, os professores e as professores em formação inicial relatam suas experiências para manter a atenção dos alunos no conteúdo a ser trabalhado. Nesta direção, Freire (1996) aponta que disciplina consiste na forma como relacionamos autoridade e liberdade. Ressaltamos que o que aqui foi tomado como indisciplina foram as conversas paralelas ou a resolução de exercícios ou leituras de outras matérias em sala. Nos fragmentos que seguem, Dandara e Celina expressam suas ideias:

[os estudantes] estavam ocupados com uso de dispositivos eletrônicos ou resolvendo exercícios de matérias mais difíceis (Dandara).

A turma da bagunça era maioria. Aos poucos a turma da bagunça foi aumentado e logo eles já estavam em uma situação que nenhum dos professores aguentava mais [...] Até mesmo os alunos mais quietos e dedicados (aqueles com as melhores notas) conversavam e faziam algumas coisas durante a aula (Celina).

No relato de Dandara, fica explícito que a aula era o momento de usar os aparelhos tecnológicos; ou então, de se dedicar a matérias consideradas mais difíceis. Já no relato de Celina, é possível compreender a aula como um intervalo, dedicado a conversas paralelas e brincadeiras. García (1999) corrobora, neste sentido, dizendo que, no primeiro 
v. $8(3)$

161-180 out-dez 2018

momento da formação dos professores, em uma etapa que compreende dos 21 aos 28 anos de idade, questões disciplinares eram vistas como as mais importantes para os professores. Embora Celina não explicite, exatamente, os fatos que ocorreram durante a aula, ela ressalta que esse comportamento era generalizado, assim como acontecia na turma onde Dandara vivia sua experiência com as questões disciplinares.

De maneira semelhante, Simone também viveu seu momento no qual faceou a indisciplina em sala e tomou uma medida para deter a atenção da turma. O fragmento explicita sua posição diante da turma:

[...] eles estavam falando muito alto e eu estava tendo problemas em falar com a turma, pois não me ouviam, aí tive uma ideia que deu mais certo do que imaginei, bater o giz no quadro. [...] Tive que ralhar um pouco com eles para que fizessem efetivamente a atividade (Simone)

Podemos afirmar sem dúvidas que nem todos colaboradores dialogaram na mesma perspectiva que Freire (1995, p.80), quando esse nos coloca "respeito mútuo, [...] segurança ao perguntar, seriedade na resposta". Simone, ao comentar esse diário, fala-nos: "[...] me senti jurássica [...]". Não é difícil reproduzir técnicas as quais presenciamos, ainda na tenra idade quando começamos a refletir sobre o conceito de escola. Sendo esse um conceito abstrato, o que nos é dado como referencial de escola é o mesmo que vivenciamos enquanto estudantes, portanto, em um tempo do passado.

Logo, como professores e professoras em formação inicial, essas pessoas têm a oportunidade de [re]significar conceitos, cada uma dentro de sua trajetória pessoal e profissional. Porém aquilo em que se acredita, às vezes, distancia-se das prévias práticas escolares. Ou seja, nem sempre o educador que queremos ser é o educador que somos; visto que precisamos reeducar a nossa compreensão para esse processo de [des]construção, assim como versa Freire (1995, p.18) acerca da perspectiva formativa: "Nunca é, está sempre sendo".

\section{As frustrações que tangenciaram a formação docente}

Compreendemos que o ato de frustrar-se é um ato de ser desafiado pelo que é dado como certo e que não ocorreu como o esperado. Nessa categoria, as frustrações que tangenciaram a formação docente, 
mais precisamente no eixo a elaboração a implementação do plano de aula, estão os relatos de situações desafiadoras que perpassaram a formação desses profissionais ${ }^{8}$. Aqui, abordamos o planejamento escolar como uma atividade que tem no seu objetivo a previsão didática, a organização dos objetivos vislumbrados. No entanto, o planejamento e as atividades envolvidas na proposta precisam ser revistas e adequadas no decorrer do processo de ensino (LIBÂNEO, 1994).

Nesta contextura, a colaboradora Dandara começa sua manhã pensando se os estudantes ainda lembrariam de tópicos discutidos em sala de aula, e, assim, ela foi revisando cada etapa do plano de aula que foi previamente elaborado e revisado na orientação com a supervisora de estágio. O fragmento da narrativa que segue explicita sua fala e seu questionamento:

[...] será que ficou algo da nossa discussão passada? Com essas perguntas norteadoras em mente, me dirigi à escola repassando mentalmente as etapas do planejamento de hoje (Dandara).

O sujeito dessa narrativa compreende o seu ato de planejar como uma singularidade do seu ser professor, que espera fazer a diferença através do seu instrumento social: o ensino. Enquanto isso, Simone percebe que o seu planejamento não foi como o esperado e decide orientar a sua prática pedagógica em outra direção:

[...] aos poucos percebi que estava perdendo a atenção da maioria, alguns ainda estavam focados, participando e interessados, mas eram poucos. Então decidi improvisar (Simone).

Para Simone, não foi difícil executar as ações chaves "Refletir, avaliar, programar, investigar e transformar" (FREIRE, 1995, p.21) ao perceber que as atividades que estavam programadas para aquele grupo não interessavam no momento. Porém, independentemente, das formas com as quais as profissionais em formação inicial lidaram com a aplicação e/ou reelaboração do plano de aula, essas não foram poupadas da frustração naquele momento.

${ }^{8}$ Optamos por não mencionar aqui os desafios de experiências acerca da atenção em sala de aula, visto que esse é um eixo articulador que foi separado devido à sua extensão. 
v. 8 (3)

161-180

out-dez

2018

Passamos a discutir o eixo o sentimento de impotência, que abrange as frustrações de rever e improvisar o plano de aula que já tinha sido estruturado, expressas na fala de Dandara que diz "Saí chateada", ou de Simone que narra "Aquele dia saí me remoendo da escola". O fragmento da narrativa que segue corrobora essa avaliação:

Me senti impotente. Fiquei chateada. Fiquei braba, muito braba [...] Me senti reduzida ao prazer de vida e pela primeira vez, amaldiçoei a escola, o sistema e arbitrariedade de estar lá. Não quero voltar. Nunca pensei que desgostaria da escola. (Helena)

Este sentimento está atrelado à função de ser educador e à imagem que vamos tecendo da profissão em nós, da aprendizagem que vamos consolidando nos espaços e tempos da docência. O sentimento de frustração torna-se raivoso ou irado, ou ainda, impotente e coloca essas jovens professoras em um movimento de revisitação das práticas pedagógicas. Esse cume reflexivo que as desorganiza através das relações pessoais tão entroncadas em sala de aula leva a uma nova organização pessoal e profissional. Ferraroti (2014, p.70) aponta que:

Uma vida é uma prática que se apropria das relações sociais (as estruturas sociais), as interioriza e as reconverte em estruturas psicológicas através de sua atividade de sua desestruturaçãoreestruturação. Cada vida humana revela-se, mesmo em seus aspectos mais generalizáveis, como uma síntese vertical de uma história social.

Desse modo, o sentimento de frustração, do qual todas partilharam, culminou na terceira e última categoria de análise, intitulada a necessidade de readaptar-se e de emergir. Nesse contexto, buscamos o momento reflexivo norteado pelo sentimento de impotência, pelo sentimento de angústia, pela necessidade de ajustes do fazer docente para buscar a compreensão do Outro a partir do lugar deste.

\section{A necessidade de readaptar-se e de emergir}

A categoria a necessidade de readaptar-se e de emergir aponta para a necessidade de desconstrução e de reconstrução daquilo que consiste em ser professor e traz excertos narrativos reflexivos que explicitam a busca pela regulação do fazer docente, ou ajustes que se fazem necessários na atuação e na busca por avaliar o próprio processo 
[trans]formativo. Esta categoria é, portanto, compreendida como uma forma de organização interior, originada pelo ápice psicológico de relações pessoais, entre o que o sujeito espera da sua representação social e o ato de conscientizar-se da sua função social, em um momento reflexivo através da escritura desse processo constitutivo.

Esta categoria está dividida em dois eixos. Oprimeiro, intitulado o olhar para o Outro, faz menção ao papel dos estudantes e professores em salas de aulas lotadas, em um momento de encontro significativo entre docentes e discentes. O momento vivenciado em sala de aula que dura, em média, uma a duas horas/aula para os professores dos anos finais do Ensino Fundamental, contexto dos estágios aqui considerado, é fugaz e poucas são as oportunidades de olhar para o Outro e reconhecê-lo. O excerto que segue ilustra o movimento reflexivo da professora Helena:

Como professora e como aluna ao mesmo tempo, me sinto hipócrita cumprindo o meu papel: a assimetria de poder me incomoda, assim como isso me incomoda na minha ideologia política. Entendi que o meu ser acabou de ser confrontado com a realidade e foi desacomodado. Os alunos me reorganizaram e como tudo que se bagunça para depois se assentar, houve desconforto e dor. Olho pela janela e penso: quando chegará a hora em que eu lhes desacomodarei? (Helena)

Se a grande quantidade de estudantes se torna um empecilho didático a ser transposto, quiçá não o fosse para as relações interpessoais e as aprendizagens docentes dessa relação, por vezes, inicialmente tensionada. Assim, este eixo corrobora para a compreensão de como acontece o movimento reflexivo docente, reconhecendo o aluno e assim seguir na busca por compreender o papel de ser docente, dentre todos os papeis dispostos na vivência do indivíduo. As docentes Simone e Suzana narram a percepção do momento:

Percebi isso em alguns outros alunos: a Ana Julia, líder da turma, parece ser um exemplo de aluna, porém sempre está com cara de quem não está satisfeita com a aula; a Nathália, uma menina educada que senta bem no fundo da sala, ela parece saber bastante, porém também parece solitária sem falar com quase ninguém durante as aulas; e também o Eduardo, que é quieto durante as aulas, mas posso ver que 
V. 8 (3)

161-180 out-dez 2018

se dá vem com os outros meninos, o silêncio se dá por estar o tempo todo prestando atenção ou fazendo os exercícios. Tem outros alunos que gostam muito de falar e fazer graça e alguns que são quietos e esforçados, mas pelo que posso ver são todos bem educados. (Simone)

A professora passou uma folha de exercícios para que eles fizessem, e disse que eles poderiam pedir tanto a minha ajuda quanto a dela. Quase todos me chamaram, e eu pude perceber que eles estavam entendendo. Isso foi gratificante e novamente me fez pensar que não se deve desistir na primeira dificuldade, se fosse assim hoje eu não estaria aqui na Universidade. (Suzana)

Apenas aqueles que compreendem e se compreendem podem se organizar, internamente, na sua formação profissional. Nesta perspectiva, Josso (2014) mostra-nos que, no momento em que o sujeito se engaja na atividade formativa e se integra a sua própria trajetória de formação de forma consciente, essa se dá de maneira efetiva:

Isso implica uma presença consciente do sujeito, sem a qual falaríamos mais de "adestramento" do que de formação. É a presença consciente que nos permite falar de um sujeito de formação. O ser em formação só se torna sujeito, no momento em que a sua intencionalidade é explicitada no ato de aprender e em que é capaz de intervir no seu processo de aprendizagem e de formação para favorecê-lo e reorientá-lo (JOSSO, 2014, p.76)

A tomada de consciência é um eixo articulador que acontece no fazer da docência e está imbricado ao eixo anterior, o qual buscava olhar e reconhecer o Outro, ambos dentro da categoria a necessidade de readaptar-se e de emergir. Nesse viés, compreendemos a tomada de consciência como um momento de vislumbre dos estudantes em processo formativo, os quais após um momento reflexivo, perceberam o seu papel dentro da instituição e largaram mão daquilo que foi tomado como certo, como institucionalizado.

Neste sentido, Garcia (1999, p.154) aponta a atividade formativa de professores como algo que vai além da memória ou do saber teórico, o autor explica que o "conhecimento dos professores se organiza e se transmite com base em histórias ou casos possuidores de 
realismo, vivacidade, significação pessoal, e que implica não apenas componentes cognitivos, mas também afetivos". Afetividade foi a palavra de busca e encontro, para Helena, sujeito que expressa através da sua escolha lexical o gostar romantizado daquela que assume o papel afetuoso, tão erroneamente associado ao exercício de uma professora, mas que para ela é um gostar que toma forma pelo apreço e por sentir prazer no campo profissional:

De qualquer forma, foi bom estar lá. Estar presente. E eu tive certeza, numa só manhã, do papel social que eu quero ocupar no mundo. Talvez não da forma pré-estabelecida, da normatividade da sala. Mas não dá pra negar que eu gosto de estar lá. Gosto da Larissa9. Gosto da escola. Gosto do papel que quase desempenho. (Helena)

Helena encontra-se na repetição do gostar, mas não no infinitivo e sim no presente. De forma ainda inconsciente, a docente em formação toma ciência da volatilidade dos papeis sociais nos dias atuais e compreende que o seu interior se transforma naquilo que não é palpável, mas remoído e sentido pelas marcas da memória. Talvez, o tempo traga uma outra nuance a esse papel social, sendo a memória tão caótica e subversiva (FERNANDES; GARNICA, 2012), a ponto de transformar e mutilar aquilo antes dado com tanta assertividade.

Assim, o processo que eles faceiam é também de ressignificação interior, da compreensão do ambiente em que está inserido e do papel que desempenha nesse, desconstruindo aquilo que foi institucionalizado e construindo um papel social subjetivo, individual e mutável. Outra colaboradora se insere em nossas narrativas para discutirmos neste estudo. As palavras de Clarissa ilustram o processo:

Já estou na quarta semana de estágio e já não sou mais a mesma, cada olhar é único diante desse constante processo de metamorfose. Comigo há mais experiências, mais perguntas e menos respostas (Clarissa)

Nesse fragmento, Clarissa percebe que o ser professor ou o tornar-se é metamórfico, um deixar para trás certezas e adquirir dúvidas através da reflexão. E o mais importante: esse processo é feito de forma

\footnotetext{
9 Este nome não guarda identidade da referência realizada na narrativa de Helena.
} 
v. $8(3)$

161-180

out-dez

2018

constante. No nosso cotidiano, muitas experiências são naturalizadas e ocupam um lugar de verdade absoluta, entretanto, ao narrar, o sujeito rememora experiências vividas e as desnaturaliza, pois o contar sobre si dá-se em uma prática [meta]reflexiva, resultando em uma tomada de consciência. A exemplo do episódio narrado por Renata, que havia institucionalizado algumas características idiossincráticas, como o tom de voz e o simples ato de escrever a lápis ou a caneta ou, ainda, decidir a cor da referida caneta no seu fazer em sala de aula:

Com essa experiência, percebi coisas em mim mesma que não pensei que afetariam meu desempenho em aula [...] Também não pensei que tivesse que ter tantas decisões tomadas pensando em coisas triviais... (Renata)

Não tão distante das reflexões matutadas pelas colegas, Celina catalisa a sua tomada de consciência não pela efemeridade do tempo, como Helena; nem pela [re]acomodação das certezas por dúvidas que, embora não sejam afirmativas, são mais assertivas, como Clarissa; nem por aquilo que antes era transparência, mas que agora é obscurecido, como Renata; mas sim pelo lugar único que aquela escola ocupa, pela sua singularidade no trato com que é entendido como educação e ensino:

[...] me sinto preparada para trabalhar na escola como professora, pois sinto que fui bem acolhida nela, e gostei do modo com que o ensino é tratado, não apenas como uma obrigação, mas para fazer a diferença na vida do educando" (Celina)

Conforme aponta Ferraroti (2014, p.71), o método narrativo consiste de "uma via não linear, frequentemente cifrada, que exige, para se deixar de percorrer, a invenção de chaves e métodos novos", e esse inovar não só requer da ciência o próprio aprimorar-se, mas do sujeito, no [re]significar-se e no compreender-se ator da sua própria história ou estória (pois a narrativa nos permite isso: o que alguns chamam de invenção, chamamos de ressignificação pelas nuances da memória), afinal "todos os indivíduos são livres para escolher criar para suas vidas os significados que quiserem (e puderem)" (BAUMAN, 2001, p.244).

No catalisar da nossa formação, somos protagonistas necessitando de catarse, de inspiração e de autonomia consciente. 
[Res]significamos nossos sujeitos ao ser leitor ou escritor, ao ter audiência e também na solidão, no fluxo do tempo, das dúvidas e da territorialidade, mas principalmente ressignificamos e protagonizamos quando dispomos de tempo "de pausa, e descanso, 'tomar seu tempo': recapitular os passos já dados, examinar de perto o ponto alcançado e a sabedoria (ou imprudência, se for o caso) de o ter alcançado" (BAUMAN, 2001 p.240). Por isso dispomos de narrativas, nas quais encontramos os cernes de mudança de cada sujeito e tomamos como ferramenta para a tomada de consciência do saber-fazer. Seja qual for o lapso, o vetor da catarse ou o impulso de vida, que mais docentes disponham de tempo para encontrar o seu atuar em uma formação consciente do professorado.

\section{Considerações finais}

A fim de compreendermos a pertinência do diário reflexivo como ferramenta no processo formativo e, na direção de considerarmos as identidades de ser professor, explicitamos importantes aspectos recorrentes em cada narrativa, os quais culminam não em apenas descrever e escrever, mas também de resistir às escrituras (despendendo tempo, memória e esforço). Os escritos e a leitura dos diários são, por conseguinte, ferramentas valiosas para a tomada de consciência nesse processo formativo contínuo que é a aprendizagem da docência.

A categoria os enfrentamentos na vivência em sala de aula trouxe-nos relatos de insegurança pessoal e profissional dos sujeitos envolvidos e também as práticas de professores em formação inicial face ao comportamento dos educandos na escola, como o uso da tecnologia ou a importância do ensino de línguas frente a outras disciplinas. Essa categoria culmina em relatos imbricados nas frustrações que tangenciaram a formação docente, quando o plano de aula, que era visto como eixo norteador, precisou ser revisto e quando situações inesperadas geraram o sentimento de frustração. Essa frustração, por sua vez, gerou um impulso para que as professoras pudessem rever e readaptar suas práticas docentes, descritas em a necessidade de readaptar-se e emergir.

Nessa última categoria foi observado um movimento de reconhecer o Outro para, então, compreender o papel social do que é ser docente. Os relatos reunidos nessa categoria corroboram para compreendermos que o sujeito em formação inicial necessita de tempo para pensar (BAUMAN, 2001), para submergir das dificuldades que 
v. 8 (3)

161-180

out-dez

2018

faceiam o cotidiano. Esse processo lento e gradual pode ser catalisado por diversos vetores, mas mantém o processo da escrita reflexiva como apogeu. Assim, apreendemos que o sujeito está em formação constante e que esse se [res]significa perante frustrações, para, então, tornar-se consciente desse movimento contínuo.

A escrita dos diários de classe, bem como a reflexão sobre eles possibilita o entendimento crítico dessa ferramenta como proposta de trabalho e prática formativa docente. Pineau e Le-Grand (2012, p.22) apontam que "ignorar ou ter como ilegítimas essas escritas pessoais, é desconhecer a dimensão simbólica do ser humano, que precisa se inscrever para ser e construir o seu devir". Na perspectiva de finalizar esta discussão, um fragmento da narrativa da professora Dandara corrobora para afirmarmos que o diário é capaz de possibilitar o cronotopo, o qual entendemos a partir da teoria desenvolvida por Bakhtin (2010). Este autor (2010, p. 211) assinala que, a "interligação fundamental das relações temporais e espaciais, artisticamente assimiladas em literatura, chamaremos de cronotopo (que significa 'tempo-espaço')". Por conseguinte, assim definirmos cronotopo, como o lugar e o tempo para aquele que escreve e que se reorganiza no seu fazer e refazer pedagógicos:

Saí chateada, mas agora, enquanto escrevo e reflito sobre a minha prática, penso que haverá altos e baixos (aliás, sempre houve) que uma aula não é igual a outra e que esse embate interno é necessário para que o nosso fazer pedagógico esteja em constante construção (Dandara).

Assim, foi possível perceber a forma como cada professora em formação inicial constitui-se no processo da sua escrita, como olhou para o Outro e também olhou para si, através do diálogo consigo mesmo e com o Outro, na dimensão de tornar-se uma aprendiz consciente no espaço da Licenciatura. Esse texto permite que entendamos que a tessitura de ideias em forma de diários como proposta de trabalho e como prática pedagógica na formação inicial de professores é a possibilidade de uma formação profissional crítica e [trans]formadora. Neste sentido, entendemos que a narrativa no diário associa a atividade reflexiva à escrita e à leitura compartilhada, permitindo uma observação mais profunda dos acontecimentos vivenciados e, por conseguinte, a constituição identitária de um profissional autocrítico. 


\section{Referências}

BAKHTIN, M.M. A Estética da Criação Verbal. São Paulo: Martins Fontes. 1992.

BAKHTIN, M.M. Questões de literatura e de estética: A Teoria do Romance. Tradução Aurora Fornoni Bernardini et al. 6. ed. São Paulo: HUCITEC, 2010.

BAKHTIN, M. M.; VOLOCHÍNOV, V. N. Marxismo e Filosofia da Linguagem. São Paulo: Editora HUCITEC, 2010.

BAUMAN, Z. Modernidade líquida. Rio de Janeiro: Jorge Zahar Editora,. Trad. de Plínio Dentzien, 2001.

BOLZAN, D. P. V. Enciclopédia de Pedagogia Universitária: glossário. V. 2. Marília Costa Morosini. (Ed.) Brasília: Instituto Nacional de Estudos e Pesquisas Educacionais Anísio Teixeira/RIES, 2006. 610p.

CHENÉ, A. A narrativa de formação e a formação de formadores. In: NÓVOA, António; FINGER, MATTHIAS (Org). 0 método (auto)biográfico e a formação. Natal, RN: EDUFRN, p 121-132, 2014.

DELORY-MOMBERGER, C. Biografia e educação: figuras do indivíduo projeto. Natal: EDUFRN, São Paulo: PAULUS, 2008

CONNELLY, F. M.; CLANDININ, D. J. Relatos de experiencia e investigación narrativa. In: LARROSA, Jorge et al. Déjame que te cuente: ensayos sobre narrativa y educación. Barcelona: Editorial Laertes. 1995. p. 15-59.

FERRAROTI, F. História e histórias de vida: o método biográfico nas ciências sociais. Natal, RN: EDUFRN, 2014. Trad. Carlos Eduardo Galvão e Maria Conceição Passeggi.

FERNANDES, D. N.; GARNICA, A. V. M. Temporalidades Distintas: um estudo sobre a formação de professores de matemática no Maranhão. In: FERREIRA, A.C.F.; BRITO, A.J; MIORIM, M.A. (Orgs). Histórias de Formação de Professores que Ensinaram Matemática no Brasil. 1. ed. Campinas: Ilion, 2012, v.1, p. 175-189.

FREIRE, P. À Sombra desta Mangueira. São Paulo: Editora Olho d'agua, 1995.

FREIRE, P. Pedagogia da Autonomia: saberes necessários à prática educativa. São Paulo: Paz e Terra, 1996.

FONTANA, R. C. Como nos tornamos professores? 3. ed. Belo Horizonte: Autêntica Editora, 2010.

JOSSO, M. C. Da formação do sujeito...Ao sujeito da formação. In: NÓVOA, António; FINGER, MATTHIAS (Org). 0 método (auto)biográfico e a formação. Natal, RN: EDUFRN, p 57-66, 2014.

LIBÂNEO, J. C. Didática. São Paulo: Cortez, 1994.

LEFFA, J. V. (Org.). Aspectos políticos da profissão do professor de Línguas Estrangeiras. O professor de línguas estrangeiras: construindo a profissão. 2 . ed. Pelotas: Educat, 2008 pp. 353-376 
v. 8 (3)

161-180

out-dez

2018

GARCÍA, C. M. Formação de Professores: para uma mudança educativa. Porto: Porto Editora, 1999.

MOISÉS, L. P. Lição de Casa. In: Aula: aula inaugural da cadeira de semiologia da universidade de França. São Paulo: Cultrix, 2013. pp. 53-107.

NÓVOA, A. Vidas de Professores. 2. ed. Porto: Editora Porto, 1995. p. 11-25.

PINEAU, G.; LE GRAND, J. L. As histórias de vida. Natal, RN: EDUFRN, 2012. Trad. Carlos Eduardo Galvão Braga e Maria da Conceição Passeggi.

POLLAK, M. Memória e Identidade Social. Estudos Históricos, Rio de Janeiro, 1992, p. 200-212.

PORLÁN, R.; MARTÍN, J. El diario del profesor: un recurso para la investigación en el aula. Sevilla: Díada, 1997.

RODRIGUES, N.C; PRADO, G.V. Investigação Narrativa: construindo novos sentidos na pesquisa qualitativa em educação. Revista Lusófona de Educação. v. 29, pp 89-103, 2015.

SOUZA, E. C. de. Campos y territorios de la indagación (auto)biográfica em Brasil:Redes de investigación y educación rural. Revista Mexicana de Investigación Educativa, v. 19, n. 62, p. 787-808, 2014.

TELLES, J. A. A trajetória narrativa: histórias sobre a prática pedagógica e a formação do professor de línguas. In: GIMENEZ, Telma (org). Trajetórias na formação de professores de línguas. Londrina: Ed. UEL, 2002.

ZABALZA, M. Diários de aula: um instrumento de pesquisa e desenvolvimento profissional. Porto Alegre: Artmed, 2004. Trad. de Ernani Rosa. 